\title{
Building an Institutional Framework for Nanotechnology Industry in Russia
}

\author{
Daniil P. Frolov \\ Head of Department of Marketing, Volgograd State University, Volgograd, Russia
}

Victor O. Moseiko

Professor of Management Department, Volgograd State University, Volgograd, Russia

Sergei A. Korobov

Head of management department, Volgograd State University, Volgograd, Russia, Prospekt Universitetskiy, 100, Volgograd, Russia, 400062

Email: ecodev@mail.ru

Doi:10.5901/mjss.2015.v6n3s6p81

\section{Abstract}

Russia is one of the most active investors in nanotech industry in the world. At the same time, formation of the Russian nanoindustry restrains the undeveloped institutional environment and lack of an integrated approach to nano-industrial policy. In this article actual problems of institutional regulation of the nanotechnological industry in Russia are considered. The main problem of regulation of nano-industry is discrepancy of definitions and classifications of nanotechnologies. Russian nano-industrial policy has inconsistent character, it combines elements of policy of import substitution and new industrial policy. At modernization of the Program of development of nano-industry in the Russian Federation it is necessary to construct regulatory policy on the principles of new industrial policy. Differentiation of methods and instruments of support of nano-industrial firms and research organizations on the basis of the detailed classification of nanotechnologies is necessary. Strategy of development of nanotech industry has to include a complex of the segment-focused marketing strategies of development of different types of nanotechnologies and nanotechnological productions. Special value has active involvement of a wide range of stakeholders of nano-industry in dialogue with the state on minimization of barriers and increase of efficiency of generation and commercialization of innovations, strengthenings of requirements to safety and developments of voluntary institutional initiatives. Stimulation of interdisciplinary integration and interindustrial collaboration within convergence of quickly developing technologies is perspective. The complex interrelation of the directions and forms of regulation and support of nano-industry on micro, meso - and macrolevels will allow to increase efficiency of its regulation and development of national innovative system in general.

Keywords: nanotechnologies, nano-industry, institutes, regulation, nano-industrial policy.

\section{Introduction}

Nano-technologies are a conglomerate of the most rapidly developing technologies, which have the potential to be widely used in various industrial sectors. Russia has been actively developing world-class nano-industry and now it takes the $4^{\text {th }}$ place by the volume of state allocations on nanotechnologies and is among the top 10 countries by the number of research articles on nano-science. However, Russian nano-industry institutional regulation faces numerous problems, which restrain its development. Some of these problems are universal (i.e. they arise in almost all countries, which put special efforts into nanotechnologies' advance), some of them are typical of a particular country. Nanotechnologies institutional regulation problems analysis in Russia may be of great help for other developing countries and high-tech sectors.

The analysis of the new technologies' institutional environment development is usually the weak point in technological evolution conception (Frolov, Ryzhkin, 2012; Frolov, 2012). Most scholars are concentrated on studying science-technical progress dynamics and forms, and especially on the origin and diffusion mechanisms of big innovation "clusters". So, most scholars just don't take into consideration the institutions' influence. For example, according to innovations paradigm conception by M. Hirooka, the diffusion of new technologies, which initiate the economy's entrance to market development and expansion, is followed by certain insignificant institutional changes (Hirooka, 2006, p. 25). 
According to C. Perez, economic systems' evolution in the long-term period is the result of the technical-economic and socio-institutional spheres' connections and breakups (Perez, 2004, p. 218-219). At the same time socio-institutional factors take the restraining role. As R. Nelson notes, the technological evolution institutional forms and mechanisms are barely studied and their analysis bases on quite abstract understanding of what institutions are (Nelson, 2002, p. 18).

One of the main problems of the nanotechnologies strategic development are the institutional "deficits" (Hodge, Bowman, Maynard, 2010). They appear in government regulation authorities' infrastructural fragmentation, bad key actors' coordination and political system's unpreparedness to implementing proactive policy on taking responsible decisions in technological sphere (Roco, Williams \& Alivisatos, 1999, p. 453). This situation may be caused by the inertia of the technology regulating stereotypes and this inertia reflects the 'path dependence' effect. Modern systems of technological control have been elaborated for minimizing the steam engine externalities and other "pre-computer" economic technologies. These modern systems are based on the assumption that most technogenic problems are local and the technologies are changing rather slowly, that's why all difficulties connected with them will be indentified in time and the regulatory measures will be of situational reactions fragmentary character. This approach doesn't correspond to modern economic challenges (Davies, 2009, p. 24).

Institutional reaction to the technological advance implies a wide range of possible models, beginning from a state ban (like with cloning people) and ending with the absence of special legislature (like in the case of social networks and domain name systems in the Internet). Numerous experts still discuss whether it is still worth considering the nanotechnologies' regulation on their developmental stages. At the same time, a big variety of flexible "nano-specific" regulatory norms are essential for the sustainable and secure nano-industry's development. These regulatory norms' degrees of freedom and control should be linked with the nanotechnologies' life stages.

Scientists and politicians are interested to avoid that unpleasant situation with GMO products. This is why nanoethics has appeared almost at the same time with nano-science. Nano-ethics studies social, ethic, and legal aspects of atom-molecular constructing. Nanotechnologies remain a "socially affecting technology". In particular, the European Parliament has banned nano-containing food in 2010 (together with the ban to produce food from cloned animals), giving the following comment "until the danger for peoples' health is eliminated) (David \& Thompson, 2008). Producers and regulators of nano-industry are obliged to make conclusions out of the negative biotechnologies' use. Firstly, comprehensive assessment and testing of potential risks to people's health and environment are necessary for the innovative hi-tech goods to enter the market. Secondly, nanotechnologies regulation should be based on a preventive principle. Thirdly, professional and public discussion on free and obligatory nano-products labeling or their combination variants is required (Mehta, 2004, p. 34-39).

\section{Methods and Materials}

Nano-industry is inter-industry complex of the production and service types of economic activities connected with creation, sale and service of nanoproduction - the nanotechnological and nanocontaining goods, nanotechnological works and services, - and also expansion of its resources (including intellectual capital, information and infrastructure).

The institutionalization of nano-industry is realized in four directions:

- formation of the nanotechnological institutions - types of economic activity connected with nanotechnologies, including specialties, professions, forms of consumption and leisure (nanolevel), types of innovative business (microlevel), industries and interindustry complexes (macrolevel);

- the statement of stakeholders, constituents and groups of influence which collective interests directly or indirectly correspond to development of nanotech industry;

- creation of institutes of development and the bodies regulators of nano-industry providing its operated and controlled evolution, and also networks of nanorelevant enterprises and organizations;

- development of the formal and informal institutional environment, including rules, standards, norms, values, stereotypes and beliefs.

The research goals of this article are: to define the nanotechnology's notion and classification; to suggest a general model of nano-industrial institutional regulation; to ground Russian nanotechnological industry's institutional environment development directions.

Methods of research include the complex and comparative analysis of strategic documents in the field of nanoindustry, the institutional analysis of technological development, the critical analysis of the state nanoindustrial policy. 


\section{Results}

Strict terminology and comprehensive understanding of what nanotechnologies are is necessary for efficient institutional nano-industry regulation (Lim, 2009). Conventional definition of nanotechnologies by their correlation with 100 nanometers scale appeared in the National Nanotechnology Initiative, USA (1999) (Roco, Williams \& Alivisatos, 1999), however it still being criticized, although alternative definitions are only under discussion. A particle worth 99 nanometers possesses barely less unique features than that of a 101 nanometer particle. That's why various academic organizations, associations and agencies suggest increasing the upper limit of the nano-scale up to 200, 300, and even 500 and 1000 nanometers. However the definition of nanotechs (like any global technology) is a complicated political-economic process, implying multistage coordination of scientific definitions with numerous interests of hi-tech business lobbyists.

The inexact definition of the nano-industrial production and its classification still remain a very important problem for institutional regulation. A countless number of badly structured notions, used for clarifying nano-industry's productionnano-products, nano-goods, products with nano-components, goods with nano-features, nano-industrial production, nanotechnological production, nano-containing products, nano-transformed goods and etc. are widely used and their classifications still remain inconcrete and eclectic. This tendency is typical of foreign science. Without the agreement on defining the notions and their interpretation the classification of nano-industry's objects, processes and products becomes more and more complicated, and this in turn causes the increase of transactional costs of nano-technologies' national legislature elaboration.

The following classification has been introduced by the Russian Federation Government Decree (2011 г.):

- "A" category nano-industry production (primary nanotechnology production): goods, being nano-components (such as nano-object and nano-systems), including raw materials and semi-finished products for producing nano-industrial goods of "B", "C" and "D" categories;

- "B" category nano-industry production (products with nano-components): goods, containing nano-components (containing "A" category nano-industry production);

- "C" category nano-industry production: services (goods, which don't contain nano-components), when providing (producing) which nanotechnologies and/ or nano-components were used (such as "A" category nano-industry production);

- "D" category nano-industry production: goods, being special nanotechnological equipment.

This exact classification of nano-industrial production is used as the basis for statistical observance of the nanotechnological organizations' and enterprises' activity.

Out of all the enumerated categories, the "B" category nano-industry production (goods, containing nanocomponents ) seems to be the most inexact category. Such products can be regarded as nano-industry products only if its nano-components create brand-new functional and consumer characteristics and the components themselves are inseparable parts of the goods produced. However, it is still hard to define the novelty and uniqueness degree or the advance of functional and/ or consumer characteristics of a nano-product. Thereby we need to elaborate a special multicriteria assessment system. If we include the services, when providing (producing) which nanotechnologies and/ or nano-components were used, into the range of nano-industrial services, then we'll get broader opportunities for the ungrounded overstating of nano-products production volumes ("B" category nano-industry production).

After having compared all existing nano-technologies' conceptions, we came to the conclusion that all of them are substantially dual. It's worth noting that there is no general view on what nano-technologies are. This notion is used to denote 2 completely different technological classes:

1. Turn-down nano-technologies. A turn-down nano-technology is a heterogenic complex of miniaturization methods and instruments, which allow to create "endlessly small" objects with nano-metric precision. The main "to cut whatever is not needed" operating principle doesn't differ from traditional mechanic way of processing, by "subtracting" the material from the half-finished product's body. However, creating new nano-sized materials promotes the increase of production and social progresss effectiveness. Microelectronics, micromechanics, electronic lithograph, the production of superdispersed materials (like powders) and etc. are all the examples of nano-materials.

2. Bottom-up nanotechnologies. A bottom-up nanotechnology is a range of means, providing purposeful manipulations with separate atoms and molecular self-assembly. The main "to add whatever is needed" operating principle is the basis of new additive way of production, providing a new qualitative level of resourcesaving by radical optimization of losses, wastes ecological impact. So far, additive manufacturing (AM technologies) correlates more with rapid prototyping technologies on the basis of products' digital description. In addition to it, AM technologies will cover all stages and spheres of products' additive synthesis use, whether 
it is a prototype or line manufactured product. Bottom-up nano-technologies are the basis of additive manufacturing way. Turn-down technologies are a transitional step on the way to bottom-up technologies. In this sense, the term "nano-technologies" acts like an "umbrella brand", covering a broad range of research and elaborations, including non-pioneering research and elaborations. It is no coincidence that turn-down nanotechnologies got close attention in the «Nano-2» report by the National Science Foundation, USA in 2010 (Roco, Mirkin \& Hersam, 2010; Roco \& Bainbridge, 2013). Thus, we consider that Nano-industry Development Programme in the Russian Federation needs modernization, because now this Programme does not correspond to contemporary technological development tendencies.

We consider it reasonable to continue further advance of the existing nano-industry production classification. First of all, we should make the distinction between primary and secondary nanotechnological production. Unprocessed nanomaterials (nano-components or "A" category production) belong to primary nanotechnological production. Semi-finished products for nano-industry (nano-intermediates) belong to secondary nanotechnological production. Secondly, we should distinguish nano-containing and nano-transformed production. Nano-containing production includes many products, which comprise nano-components and nano-intermediates, and which can be produced without using special nanotechnological equipment. Nano-transformed products are manufactured with the application of extremely complicated atom manipulating and molecular modelling technologies. This classification version helps to differentiate qualitatively specific nano-products types and increase the condition and dynamics' assessment precision in nanoindustrial economy.

A hierarchical model of a "regulatory pyramid" was presented in the "Regulation and standards development in nanotechnologies" report in 2011. This model united 4 modes: free self-regulation (codes of responsible conduct, riskmanagement, public records), guides and standards (ISO, OECD, national, sectoral), obligatory self-regulation (obligatory records and etc.) and directive regulation. This hierarchical model allows to view free self-regulation and directive regulation as nano-technology institutional policy "poles". The model's fourth mode is more typical of Russia and it provokes the whole regulation system's instability with practically no developed free institutional initiatives.

We suppose that proactive institutional regulation in nano-industrialization is what we need as well. The existing control mechanisms should be adapted to specific nanotechnologies and nano-materials application problems. In particular, there is a necessity for the elaboration of standards and instructions for cosmetics, food, occupational hygiene and nano-industries workers protection, ecological safety, medical devices, pharmaceutical products and etc. Additionally, the point of unifying nano-production's measurement units, standardization and metrology, nano-materials and nano-products typology and classification is under discussion. Providing information on the products' safety (marking, certifying and creating nano-materials' and products', containing nano-materials database) is an inalienable part of modernizing institutional regulation as well. Solving all these problems is in priority, however the point of nano-products' safety requires urgent attention.

Russian Federation nano-industrialization regulation policy is considered to be reoriented at the following principles: focusing on the formation of innovative ecosystem, stimulating national and foreign regions' cooperation, macro- and microregulation principles, methods and tools priority coordination. Approaches to regulating nano-industry by the state have to be reconsidered, the state should provide the transition from subject to network, from object to the environment and from project to process regulation. This will mean the evolutionary transition of nano-industry state regulation priorities to stimulating network forms of self-organization (including cluster initiative), national innovation activity support environment, increasing the significance of long-term evolutionary processes of various nanotechnological activities' institutionalization.

Russian nano-industrial policy is currently a contradictory combination of instruments and measures of the import substitution measures (dating back to 1960-1970) and the so-called new industrial policy, based on flexible, interactive and dynamic regulation methods. Thus, the Nano-industry Development Programme in the Russian Federation up to 2015 includes a range of goals, connected with production and export volumes and world market share. This Programme is full of general and rather ambitious goal and lack flexible approach to the strategic process. The Programme is obviously focused on microregulation (creating stimuli from the bottom), namely nanotechnological infrastructure subjects formation and new works' enhanced financing. At the same time we can observe a big "gap" in this Programme of speaking about the macroeconomic policy and geopolitical decisions, which increase the costs of cooperation with foreign partners and retarger national nano-industry at the domestic market, where the demand for innovations is rather low.

The main problems of the nano-industry regulatory policy in Russia are the bad use of successful projects scaling technique in the spheres of small and medium businesses and insufficient implementation of the world's best experience. Besides, autnonomized nano-industry prevails over the intersectoral interaction of rapidly developing technologies' subjects. As a consequence, the proportion of R\&D private capital expenses in Russian Federation made up 5:1 (2013) 
and 1:2 in the USA and Italy, 1:4 in France, 1:5 in Switzerland, 2:3 in Japan and 4:3 in Germany in the same year (OECD, 2013). In the Russian Bio-Technologies Complex Development Programme adopted in 2012 and up to 2020, nano-industry is just slightly mentioned among the priority investment spheres and at the same time there is nothing said about the mechanisms of providing interaction of the nano-industry and bio-technologies.

\section{Conclusions}

Establishing a hi-tech industry in Russia is a very ambitious image mega-project with local external effects which emphasize that there is no industrial and or science-technological system in Russia so far. When modernizing the Nanoindustry Development Programme in the Russian Federation, it essential to create basic regulatory policy on the principles of new industrial policy, which would imply: the differentiation of support methods and tools on the basis of nano-technologies' detailed classification; the elaboration of a complex of segment-oriented various nano-technologies and nano-production's market development strategies; involving a wide range of nano-industry stakeholders into the dialogue with the state on minimizing the barriers and increasing innovations' generation and commercialization, on enhancing safety requirements and on the elaboration od free institutional initiatives; stimulating inter-disciplinary integration and inter-sectoral collaboration in the flow of rapidly developing technologies convergence; providing complex interconnection between the regulation forms and nano-industry support on micro-, meso- and macro-levels.

\section{Acknowledgements}

This work was supported by the Russian Foundation for Humanities (projects 13-32-01033 and 15-12-34012).

\section{References}

David, K. and P.B. Thompson (eds.). (2008). What Can Nanotechnology Learn from Biotechnology? Social and Ethical Lessons for Nanoscience from the Debate over Agrifood Biotechnology and GMOs. Elsevier, Boston, MA. ISBN: 978-0123739902, pp: 343.

Davies, J.C. (2009). Oversight of Next Generation Nanotechnology. PEN, vol. 18. http://www.nanotechproject.org/process/assets/files/ 7316/pen-18.pdf. (Accessed on February 17, 2015).

Frolov, D.P. and V.V. Ryzhkin. (2012). Upravleniye institutsionalnoy politikoy v sphere nanoindustrii [Management of institutional policy in the sphere of nanoindustry]. Vlast, 2: 63-68.

Frolov, D.P. (2012). Institutsionalnaya logika technologicheskogo progressa (sluchay nanotechnologiy) [Institutional logic of technological progress (case of nanotechnologies)]. Journal of Institutional Studies, 4 (1): 49-64.

Hirooka, M. (2006). Complexity in discrete innovation systems. E:CO Annual, 8: 68-97. ISBN13: 978-0-9791688-2-6.

Hodge, G.A., D.M. Bowman and A.D. Maynard (eds.). (2010). International Handbook on Regulating Nanotechnologies. Edward Elgar. ISBN-13: 978-0857931672, pp: 586.

OECD. (2013). Key Biotechnology \& Nanotechnology Indicators: a Comparison. http://www.oecd.org/sti/biotech/KNI_KBI_Nov_2013.pdf. (Accessed on February 17, 2015).

Lim, D. (2009). Biotechnology Industry, Statistics and Policies in Korea. Asian Biotechnology and Development Review, 11 (2): 1-27.

Mantovani, E. and A. Porcari. (2011). Development in Nanotechnology Regulation and Standards. Observatory Nano, № 3. http://www.nanotec.it/public/wp-

content/uploads/2014/04/ObservatoryNano_Nanotechnologies_RegulationAndStandards_2011.pdf. (Accessed on February 17, 2015).

Mehta, M.D. (2004). From Biotechnology to Nanotechnology: What Can We Learn From Earlier Technologies? Bulletin of Science, Technology \& Society, 24 (1): 34-39. DOI: 10.1177/0270467604263119.

Nelson, R.R. (2002). Bringing institutions into evolutionary growth theory. Journal of Evolutionary Economics, 12 (1/2): 17-28. DOI: 10.1007/s00191-002-0108-X.

Perez, C. (2004). Technological Revolutions, Paradigm Shifts and Socio-institutional Change. In: Globalization, Economic Development and Inequality: An alternative Perspective, E. Reinert (ed.). Edward Elgar, Cheltenham: Northampton, pp: 217-242. ISBN: 1858988918.

Roco, M., C. Mirkin and M. Hersam (eds.). (2010). Nanotechnology Research Directions for Societal Needs in 2020: Retrospective and Outlook. Springer. ISBN: 978-94-007-1168-6, pp: 690.

Roco, M.C. and W.S. Bainbridge. (2013). The new world of discovery, invention, and innovation: convergence of knowledge, technology, and society. Journal of Nanoparticle Research, 15: 1946. DOI: 10.1007/s11051-013-1946-1.

Roco, M.C., R.S. Williams and P. Alivisatos (eds.). (1999). Nanotechnology research directions: Vision for the next decade. IWGN Workshop Report. National Science and Technology Council, Washington, DC. http://www.wtec.org/loyola/nano/IWGN.Research. Directions/IWGN_rd.pdf. (Accessed on February 17, 2015). 
